\title{
A new type of transient diabetes mellitus of infancy?
}

\author{
J J MCGILL AND D M ROBERTON \\ Department of General Paediatrics, Royal Children's Hospital, Melbourne, Australia
}

SUMmARY Two male siblings with transient diabetes mellitus were of normal birth weight, were asymptomatic, and did not require treatment with insulin. This may be a previously undescribed disorder or part of the range of transient diabetes mellitus of infancy. Previously reported infants with transient diabetes mellitus of infancy have usually been small for gestational age and have presented with glycosuric dehydration, infections, or growth failure. Insulin concentrations after oral glucose challenge showed inadequate insulin secretion with respect to the degree of hyperglycaemia in these children. Autosomal dominant inheritance may occur in some families with this disorder, and parents of some affected children may also have had asymptomatic or unrecognised transient diabetes mellitus of infancy. Leucocyte histocompatibility antigen typing of this family did not show any association of specific antigens with transient diabetes mellitus of infancy in the affected children.

Transient diabetes mellitus of infancy is a disorder of carbohydrate metabolism of unknown aetiology. The majority of cases reported have been small for gestational age term infants presenting in the first 6 weeks of life with glycosuric dehydration, infections, or growth failure. Reports of affected siblings have been few. There have been reports of three brothers with symptomatic transient diabetes mellitus of infancy ${ }^{12}$ and three affected half siblings. ${ }^{34}$ This report is of two brothers with transient diabetes mellitus of infancy who were not small for gestational age and who had an asymptomatic course without the need for treatment with insulin.

\section{Case histories}

The subjects of this report are the only children of physically healthy, unrelated parents. Their mother, aged 26 at the time of the first delivery, is a mildly mentally retarded women who suffers from recurrent depression and has some schizophrenic traits. Their father, who is one year younger than their mother, is illiterate and prone to physically violent outbursts. The paternal grandmother had died at the age of 26 from uncontrolled insulin dependent diabetes mellitus.

Case 1. This boy was born at 39 weeks' gestation after an uneventful pregnancy during which the only drug taken was ferrous gluconate. No glycosuria was detected during the pregnancy. Delivery was by caesarean section because of fetal distress, and his Apgar scores were 8 at one minute and 10 at five minutes. He weighed $2940 \mathrm{~g}$ at birth; the placenta was normal and weighed $520 \mathrm{~g}$. He was fed a cow's milk formula from birth. Blood glucose estimations performed on days 1 and 3 of life because he was jittery were normal.

Concern regarding his mother's ability to manage him led to his attendance at 11 weeks of age for a medical examination. He was thriving and developing normally. A routine urinalysis showed glycosuria, and the result of a random test of blood glucose concentration was $15 \mathrm{mmol} / \mathrm{l}(270 \mathrm{mg} / 100$ $\mathrm{ml}$ ). During admission for investigation it was noted that he required his wet nappies to be changed at least hourly.

Treatment with insulin was not considered necessary as he continued to grow along the 90th percentile for height and weight. He had persisting hyperglycaemia (blood glucose concentrations ranging from 14.0 to $20.4 \mathrm{mmol} / \mathrm{l} \quad(252-368$ $\mathrm{mg} / 100 \mathrm{ml}$ )) and glycosuria until the age of 5 months when his blood glucose concentrations returned to normal. He has remained normoglycaemic and has continued to thrive and develop normally, his most recent assessment being at the age of $3 \frac{1}{2}$.

Case 2. The brother of case 1 was born at term weighing $3140 \mathrm{~g}$. The pregnancy had been uncomplicated, and the only drug taken was ferrous gluconate. No glycosuria was detected during the preg- 
nancy. Delivery was by elective caesarean section and initially he required intermittent positive pressure ventilation through a face mask. His Apgar scores were 4 at one minute and 7 at five minutes. The placenta weighed $750 \mathrm{~g}$ and had a gritty maternal surface but was otherwise normal. Breast feeding was begun, but at 6 hours of age he was noted to be jittery and his blood glucose concentration was $1.2 \mathrm{mmol} / \mathrm{l}(21.6 \mathrm{mg} / 100 \mathrm{ml})$. After a supplemental feed the blood glucose concentration was $7.2 \mathrm{mmol} / \mathrm{l}(130 \mathrm{mg} / 100 \mathrm{ml})$, and his symptoms resolved.

On the 15th day of life the result of a random test of blood glucose concentration was $23.5 \mathrm{mmol} / \mathrm{l}$ (423 $\mathrm{mg} / 100 \mathrm{ml}$ ), and glycosuria was present. During investigation he too was noted to require his wet nappies to be changed at up to hourly intervals.

After five weeks breast feeding was ceased. His weight increased from the 10th to the 70th percentile, and he made normal developmental progress. Although treatment with insulin was considered because of the hyperglycaemia, it was withheld because of his poor social circumstances and his satisfactory growth. Hyperglycaemia (random blood glucose concentrations $11 \cdot 1-32 \cdot 1 \mathrm{mmol} / \mathrm{l}(200-578$ $\mathrm{mg} / 100 \mathrm{ml})$ ) and glycosuria persisted until 9 months of age when his blood glucose concentration fell to $6.5 \mathrm{mmol} / \mathrm{l}(117 \mathrm{mg} / 100 \mathrm{ml})$ and the glycosuria resolved. He has remained normoglycaemic and was thriving when last reviewed at the age of 2 .

\section{Investigations and results}

A glucose tolerance test, including the measurement of plasma insulin concentrations, was performed at the age of 13 weeks in case 1 and 18 days in case 2 (Table). Antibodies against insulin were not detected in serum from case 2 and his mother taken 18 days after birth nor in serum from case 1 when tested at the age of 2 years. Antibodies against

Table Glucose tolerance tests and plasma insulin concentrations in the two patients

\begin{tabular}{|c|c|c|c|c|}
\hline \multirow{2}{*}{$\begin{array}{l}\text { Time } \\
(\min )\end{array}$} & \multicolumn{2}{|l|}{ Case I } & \multicolumn{2}{|l|}{ Case 2} \\
\hline & $\begin{array}{l}\text { Blood } \\
\text { glucose } \\
\text { (mmol/l) }\end{array}$ & $\begin{array}{l}\text { Plasma } \\
\text { insulin } \\
(m U / l)\end{array}$ & $\begin{array}{l}\text { Blood } \\
\text { glucose } \\
\text { (mmol/l) }\end{array}$ & $\begin{array}{l}\text { Plasma } \\
\text { insulin } \\
(m U / l)\end{array}$ \\
\hline 0 & $19 \cdot 2$ & ND & $11 \cdot 9$ & $<4 \cdot 0$ \\
\hline 30 & ND & ND & $11 \cdot 8$ & $11 \cdot 0$ \\
\hline 60 & $21 \cdot 1$ & 76 & 15.0 & $4 \cdot 0$ \\
\hline 90 & ND & ND & $15 \cdot 5$ & $7 \cdot 0$ \\
\hline 120 & $20 \cdot 0$ & 111 & $16 \cdot 9$ & $8 \cdot 0$ \\
\hline 150 & ND & ND & $17 \cdot 1$ & $5 \cdot 0$ \\
\hline 180 & $16 \cdot 6$ & 32 & $16 \cdot 1$ & $4 \cdot 0$ \\
\hline
\end{tabular}

$\mathrm{ND}=$ not done

Conversion: SI to traditional units-Glucose: $1 \mathrm{mmol} / \mathrm{l} \approx 18 \mathrm{mg} / 100 \mathrm{ml}$ pancreatic islet cells, HEp2 cells, smooth muscle, mitochondria, thyroid microsomes, thyroglobulin, and gastric parietal cells were not demonstrable in the serum of either patient or their mother. Neither patient had a metabolic acidosis, and ketonuria was not present at any time. Case 1 had a normal 0830 hours plasma cortisol concentration of $260 \mathrm{nmol} / \mathrm{l}$ $(9 \cdot 2 \mu \mathrm{g} / 100 \mathrm{ml})$ at the age of 13 weeks, and a simultaneous 30 hour collection of urine contained less than $25 \mathrm{nmol}$ of cortisol.

The leucocyte histocompatibility antigen typing for the siblings showed a different inheritance of parental haplotypes for each of the children, case 1 being Aw24, A29; B8, Bw6; DR3, DR5, and case 2 being A3, Aw32; Bw4, Bw6, Bw51, Bw35; DR1, DR6.

\section{Discussion}

These brothers had the classic biochemical abnormalities of transient diabetes mellitus of infancy as reported by others-namely, transient hyperglycaemia with glycosuria without either ketonuria or metabolic acidosis being prominent features. However, although transient diabetes mellitus of infancy has been described previously in some infants with a birth weight appropriate for gestational age $e^{5-10}$ and in infants not requiring treatment with insulin, ${ }^{6} 1112$ we could find only one previous report of an asymptomatic infant being diagnosed, and he had been small for gestational age. ${ }^{12}$ Thus the infants reported here may either represent part of a broader range of transient diabetes of infancy or have a disorder not previously recognised.

There have been many suggestions as to the aetiology of transient diabetes mellitus of infancy. The possibility of a delay in the functional maturation of the beta cells of the islets of Langerhans with inappropriate insulin secretion has received most support. ${ }^{1} 212$ There is evidence in the infants reported here for abnormal insulin secretion and utilisation. The insulin concentrations from case 1 are difficult to interpret fully in the absence of a fasting insulin concentration. The apparent lack of response of the blood glucose concentration with time suggests, however, some form of insulin resistance. The insulin concentration at three hours after challenge is inappropriately low with respect to the blood glucose concentration, suggesting either a suboptimal response by the beta cells or exhaustion of their insulin supplies.

The inappropriately low concentrations of insulin found for case 2 are similar to those reported by other authors ${ }^{2} 13$ and are consistent with functional immaturity of insulin secretion by the pancreatic 
beta cells. The differing responses at the different ages at which these infants were studied may reflect events occurring during the gradual resolution of transient diabetes mellitus of infancy. The results for case 2, studied at 18 days of age, suggest absolute failure of appropriate insulin secretion in the early stages. Those for case 1 , who was investigated at age 13 weeks, show a continuing abnormality of glucose disposal in the presence of appropriate insulin concentrations and early exhaustion of insulin secretion. The lack of measurable insulin antibodies suggests that alteration of insulin secretion or function by circulating antibodies is not the cause.

An alternative explanation for the insulin responses is that the glucose concentration at which insulin is caused to be released is inappropriately high in these infants. A threshold for insulin release of $15-16 \mathrm{mmol} / \mathrm{l}(270-288 \mathrm{mg} / 100 \mathrm{ml})$ of glucose in case 1 and $17-18 \mathrm{mmol} / \mathrm{l}(306-324 \mathrm{mg} / 100 \mathrm{ml})$ of glucose in case 2 would explain the observed glucose tolerance results. If this threshold then fell with age a decrease in blood glucose concentrations and resolution of the glycosuria would occur as was seen in the infants reported here.

The occurrence of affected siblings in the families reported by Ferguson et al $^{12}$ and ourselves is most consistent with an autosomal recessive mode of inheritance. If the disorder can be asymptomatic, however, it is quite feasible that either parent of an affected neonate may have been affected similarly in infancy without the condition being recognised. This would support autosomal dominant inheritance as does the report of three paternal half siblings (two girls and one boy) with transient diabetes mellitus of infancy reported by Coffey et al, ${ }^{34}$ each of whom had a different mother.

Reports of a family history of diabetes mellitus in transient diabetes mellitus of infancy have usually been in second or higher degree relatives and often do not distinguish between the genetically distinct insulin dependent and non-insulin dependent diabetes mellitus. The completely disparate HLA typing of the brothers reported here suggests that this form of genetic analysis is unlikely to be of benefit in elucidating the inheritance pattern. Although case 1 inherited the DR3 antigen from his father, case 2 had neither DR3 nor DR4, which are the two antigens most often associated with insulin dependent diabetes mellitus. ${ }^{14}$

It is unclear whether transient diabetes mellitus of infancy has a wide range of clinical presentation, from small for gestational age infants presenting in the neonatal period with dehydration, infection, or failure to thrive to asymptomatic cases such as those reported here, or whether these siblings represent a previously undescribed disorder with abnormal glucose disposal. This question cannot be answered until the pathogenesis of transient diabetes mellitus of infancy has been defined more clearly.

We thank Dr M Hill and Dr M Dunlop for performing the insulin assays.

\section{References}

${ }^{1}$ Ferguson AW, Milner RDG. Transient neonatal diabetes mellitus in siblings. Arch Dis Child 1970;45:80-3.

${ }^{2}$ Milner RDG, Ferguson AW, Naidu SH. Aetiology of transient neonatal diabetes. Arch Dis Child 1971;46:724-6.

3 Coffey JD Jr, Womack NC. Transient neonatal diabetes mellitus in half sisters. Am J Dis Child 1967;113:480-2.

${ }^{4}$ Coffey JD Jr, Killelea DE. Transient neonatal diabetes mellitus in half sisters. A sequel. Am J Dis Child 1982;136:626-7.

5 Lawrence RD, McCance MA. Gangrene in an infant associated with temporary diabetes. Arch Dis Child 1931;6:343-56.

${ }^{6}$ Keidan SE. Transient diabetes in infancy. Arch Dis Child 1955;30:291-6.

${ }^{7}$ Lewis SR, Mortimer PE. Idiopathic neonatal hyperglycaemia. Arch Dis Child 1964;39:618-24.

${ }^{8}$ Basheer SM, Doyle EE. Transient neonatal diabetes. Ir J Med Sci 1974;143:96-100.

9 Gentz JCH, Cornblath M. Transient diabetes in the newborn. In: Advances in Paediatrics. Chicago Year Book Medical Publishers 1969;16:345-63.

${ }^{10}$ Holmes JD, Watson CE. Transient diabetes mellitus: a case report. NZ Med J 1969;70:322-3.

11 Nawrocka-Kanska B. Diabetic syndrome in intracranial haemorrhage in newborns. Pediatr Pol 1952;27:1067-71.

12 Gerrard JW, Chin W. The syndrome of transient diabetes. J Pediatr 1962;61:89-93.

${ }^{13}$ Ferguson IC. Neonatal hyperglycaemia: case report with plasma insulin studies. Arch Dis Child 1967;42:509-13.

${ }^{14}$ Serjeantson S, Kirk RL, Dry PJ, et al. HLA studies in Australian multiple-case families of juvenile onset diabetes mellitus. Med J Aust 1980;1:107-9.,

Correspondence to Dr D M Roberton, Department of Paediatrics, Royal Children's Hospital, Flemington Road, Parkville, Victoria, 3052, Australia.

Received 9 December 1985 